\title{
MEMPREDIKSI LOYALITAS NASABAH PADA BMT ABC DENGAN METODE INTERATIVE DICHOTOMISER THREE (ID 3)
}

\author{
Arief Soma Darmawan', Devi Sugianti ${ }^{2),}$ Wim Hapsoro,3) \\ STMIK Widya Pratama ${ }^{123)}$ \\ Ariefsoma24@gmail.com ${ }^{1)}$ devi.sugianti9807@gmail.com ${ }^{2)}$ wimhapsoro06@gmail.com ${ }^{3)}$
}

\begin{abstract}
Abstrak
Persaingan peusahaan semakin ketat menuntut perusahaan memberikan pelayanan yang memuaskan kepada konsumen. Dalam mempertahankan konsumen salah satu kuncinya adalah mengelola informasi pelanggan. Perusahaan akan terbantu jika mempunyai sistem informasi pelanggan dikelola dengan baik, data pelanggan yang baru ataupun data pelanggan yang lama. BMT ABC mempunyai mempunyai 4.882 nasabah, akan tetapi sampai tahun 2020 nasabah yang aktif melakukan penabungan adalah 2.392 nasabah. Dalam memprediksi nasabah yang aktif di BMT ABC menggunakan metode ID3. ID 3 adalah salah satu metode klasifikasi pada data mining decision tree (pohon keputusan). Langkah-langkah penelitan: identifikasi dan perumusan masalah, penentuan variabel penelitian, penentuan data latih, hitung gain dan entropy, membagun decision tree dengan algoritma ID3. Pada penelitian ini menggunakan atribut: jenis kelamin, usia, pekerjaan, pendidikan, status, dan setoran awal. Dari hasil perhitungan Gain dan Entropy dihasilkan 5 aturan dan menghasilkan pohon keputusan
\end{abstract}

Kata kunci: Loyalitas Nasabah, ID 3

\section{Pendahuluan}

Dengan berkembangnya teknologi pengusaha berlomba-lomba untuk mencari terobosan baru (Febtadianrano, vulandari dan laksito 2020). Persaingan antar perusahaan semakin ketat, menuntut peusahaan memberikan pelayanan yang memuaskan kepada konsumen agar perusahaan menjadi terdepan dan terbaik (izzaty 2016). Salah satu kegiatan yang dilakukan oleh perusahaan secara berkala adalah pengukuran tingkat kepuasan pelanggan (Tama 2015). Salah satu kunci untuk mempertahankan keunggulan kompetitif dengan mengelola informasi pelanggan (fauziah, hartama dan sudahri 2020). Perusahaan untuk dapat melihat pelanggan yang berpotensi atau tidak perpotensi belum diolah secara optimal, karena mengalami kesulitan dalam pengolahannya (Febtadianrano, vulandari dan laksito 2020). Perusahaan akan terbantu jika mempunyai sistem informasi pelanggan dikelola dengan baik, data pelanggan yang baru ataupun data pelanggan yang lama (Ulin dan Fatmawati 2019)
BMT ABC berdiri pada tahun 2000, dengan jumlah nasabah sampai tahun 2020 bulan januari adalah 4.882 nasabah. Akan tetapi yang aktif melakukan penabungan sampai di bulan januari 2020 adalah 2.392 nasabah yang aktif masih melakukan penabungan, nasabah yang tidak aktif 2.490 nasabah. Dengan rata-rata penabungan per bulan adalah 3.388 transaksi dengan nominal sekitar Rp 842.926.300 dalam satu bulan pada tahun 2019. BMT ABC belum dapat mengklasifikasikan pelanggan yang aktif dan tidak aktif. Maka dari itu diperlukan klasifikasi pelanggan

Untuk dapat memprediksi nasabah yang aktif dan tidak aktif pada BMT ABC dapat dikembangkan suatu sistem dengan memanfaatkan berbagai metode. Salah satu metode yang dapat digunakan adalah data mining yang dapat menggali informasi yang tersembuyi dari sebuah data, data mining dapat menemukan pola atau aturan dengan menganalisa data yang ada (Inda dan nasir 2019). Salah satu metode 
klasifikasi pada data mining adalah decision tree (pohon keputusan). Metode tersebut dapat digunakan untuk prediksi penyakit diabetes (subhan dan wibawa 2018), pengukuran kinerja PNS (adiana, sediyono dan nurhayati 2014) dan dapat digunakan untuk menprediksi loyalitas pelanggan (santoso 2014). Algoritma decision tree yang digunakan adalah algortima ID3, keuntungan menggunakan algoritma ID3 adalah membentuk pohon keputusan dengan tingkat variasi yang komplit dapat memangkas pohon menjadi lebih sederhana. (adiana, sediyono dan nurhayati 2014)

\section{Metode Penelitian}

Masalah yang dihadapi oleh BMT ABC adalah memprediksi loyalitas nasabah agar selalu aktif. Dari data nasabah yang tidak pernah di olah untuk mendapatkan informasi tentang keaktifan nasabah. Dalam melakukan prediksi menggunakan metode data mining dengan menghasilkan pohon keputusan menggunakan algoritma ID3. Dimana variabel yang digunakan adalah jenis kelamin, usia, pekerjaan, pendidikan, status, setoran awal dan yang menjadi variabel prediktor adalah keaktifan dari nasabah tersebut.

Kerangka pemikiran dari penelitian ini adalah

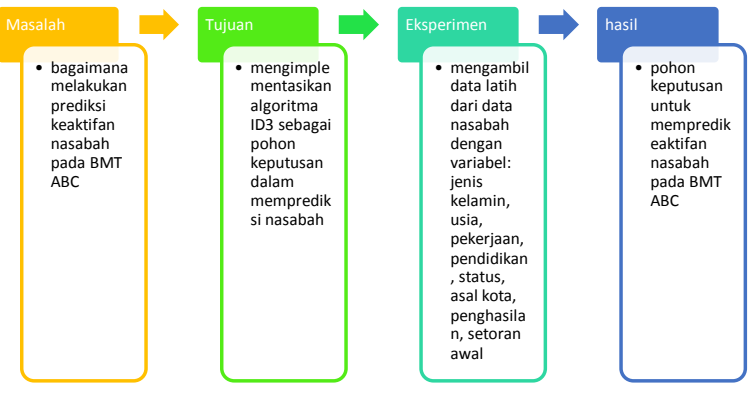

Gambar 1. Kerangka pemikiran penelitian

Dalam memprediksi keaktifan nasabah pada BMT ABC dengan tahapan yang harus dilaksanakan untuk memastikan mencapai hasil yang maskimal. Tahapan dari prosedur penelitian pertama dengan mengidentifikasi dan merumuskan masalah yang menjadi tujuan dari penelitian ini, dengan memprediksi keaktifan nasabah. Adapun langkah penelitian adalah sebagai berikut:

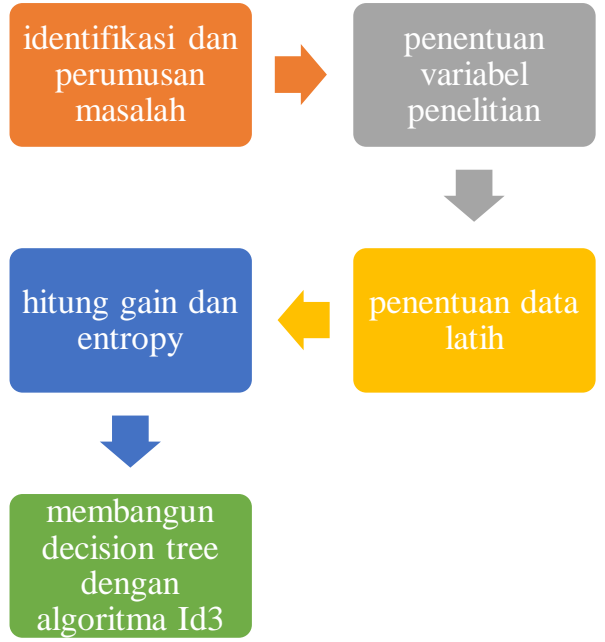

Gambar 2 Langkah Penelitian.

Dalam perhitungan atribut atau fitur sebagai akar maka dilakukan perhitungan nilai entropy terlebih dahulu dengan menggunakan rumus perhitungan sebagai berikut: (Pudjo, Handayanto dan Helawati 2013)

Entropy $(s)=\sum_{i=1}^{c}-P_{i} \log _{2} p_{i}$

Keterangan:

$\mathrm{S}=$ Himpunan Kasus

$\mathrm{P}_{\mathrm{i}}=$ Proporsi dari $\mathrm{S}_{\mathrm{i}}$ terhadap $\mathrm{S}$

Sedangkan untuk memilih atribut sebagai akar didasarkan pada nilai Gain tertinggi dari atributatribut yang ada, gain dilakukan dengan rumus sebagai berikut:

$$
\begin{aligned}
& \operatorname{Gain}(S, A)=\operatorname{Entropy}(s)- \\
& \sum \frac{|s v|}{|s|} \text { entropy }(s) \ldots \ldots \ldots . .(2)
\end{aligned}
$$

Keterangan:

Gain $(\mathrm{S}, \mathrm{A})$ = information gain dari sebuah atribut A pada koleksi $S$

$\mathrm{S}=$ Himpuanan Kasus

$\mathrm{A}=$ Atribut

$|\mathrm{Si}|=$ Jumlah kasus pada Partisi ke I

$|\mathrm{S}|=$ Jumlah kasus dalam $\mathrm{S}$

\section{Hasil dan Pembahasan}

Untuk penelitian ini menggunakan pengitungan manual dengan 9 nasabah. Dengan 6 atribut yang dijadikan sebagai acuan utnuk proses perhitungan. Berikut ini langkah-langkah penelitian yang dirinci sebagai berikut: 


\subsection{Identifikasi dan Perumusan masalah}

BMT ABC mengalami kesulitan dalam memprediksi loyalitas nasabah. Loyalitas nasabah diperlukan agar BMT dapat menjaga agar nasabah selalu aktif dalam penabungan.

\subsection{Penentuan variabel penelitian}

BMT melakukan pendataan nasabah saat pembukaan rekening baru. Tidak semua data nasabah dijadikan variabel untuk proses perhitungan prediksi. Adapun yang dijadikan variabel untuk proses perhitungan adalah: Jenis kelamin, usia, pekerjaan, pendidikan, status, dan setoran awal. Untuk varibel prediktor adalah keaktifan dari nasabah. Adapun untuk pembagian kategori dari varibel seperti tabel 1 dibawah ini

Tabel 1 pembagian kategori variabel

\begin{tabular}{|c|c|c|c|c|c|c|}
\hline Nomor & atribut & kategori & ket & \\
\hline 1 & Jenis & $\mathrm{L}$ & Laki-laki & \multirow{2}{*}{\multicolumn{3}{|c|}{$\begin{array}{l}\text { Dari data nasabah yang ada yang akan dijadikan } \\
\text { sebagai data latih terdapat } 9 \text { data nasabah yang } \\
\text { dijadikan sebagai data latih atau dataset. Berikut } \\
\text { ini adalah data latih yang disajikan pada tabel } 2 \text {. }\end{array}$}} \\
\hline \multirow{4}{*}{2} & \multirow{4}{*}{ Usia } & $\mathrm{P}$ & Perempuan & & & \\
\hline & & & & & & \\
\hline & & Dewasa & $25-59$ & & & \\
\hline & & Tua & $>59$ & & & \\
\hline Tabel 2. K & asifikasi $\mathrm{Na}$ & oah & & & & \\
\hline $\begin{array}{l}\text { jenis } \\
\text { kelamin }\end{array}$ & usia & pekerjaan & $\begin{array}{l}\text { pendidikan } \\
\text { terakhir }\end{array}$ & status & setoran awal & keaktifan \\
\hline $\mathrm{L}$ & MUDA & TIDAK & B & BELUM & SEDANG & YA \\
\hline & & BEKERJA & & MENIKAH & & \\
\hline $\mathrm{L}$ & TUA & TIDAK & B & MENIKAH & TINGGI & YA \\
\hline $\mathrm{P}$ & MUDA & BEKERJA & $\mathrm{C}$ & MENIKAH & SEDANG & YA \\
\hline $\mathrm{P}$ & TUA & TIDAK & $\mathrm{C}$ & MENIKAH & TINGGI & TIDAK \\
\hline & & BEKERJA & & & & \\
\hline $\mathrm{L}$ & DEWASA & BEKERJA & A & BELUM & SEDANG & YA \\
\hline & & & & MENIKAH & & \\
\hline $\mathrm{P}$ & TUA & BEKERJA & A & MENIKAH & TINGGI & YA \\
\hline $\mathrm{P}$ & TUA & BEKERJA & B & MENIKAH & SEDANG & TIDAK \\
\hline $\mathrm{P}$ & DEWASA & TIDAK & B & BELUM & RENDAH & TIDAK \\
\hline & & BEKERJA & & MENIKAH & & \\
\hline $\mathrm{L}$ & MUDA & $\begin{array}{l}\text { TIDAK } \\
\text { BEKERJA }\end{array}$ & B & MENIKAH & RENDAH & YA \\
\hline
\end{tabular}

\begin{tabular}{|c|c|c|c|}
\hline Nomor & atribut & kategori & ket \\
\hline \multirow[t]{3}{*}{3} & Pekerjaan & BL & Belum \\
\hline & & bekerja & bekerja \\
\hline & & Bekerja & Bekerja \\
\hline \multirow[t]{3}{*}{4.} & Pendidikan & A & SD,SMP \\
\hline & & B & $\begin{array}{c}\text { SMA, } \\
\text { D1,D2,D3 }\end{array}$ \\
\hline & & C & $\mathrm{S} 1, \mathrm{~S} 2, \mathrm{~S} 3$ \\
\hline \multirow[t]{2}{*}{5} & Status & Menikah & \\
\hline & & $\begin{array}{c}\text { Blm } \\
\text { Menikah }\end{array}$ & $\begin{array}{l}\text { Belum } \\
\text { menikah }\end{array}$ \\
\hline \multirow[t]{3}{*}{6} & Setoran & Rendah & $<500.000$ \\
\hline & & Sedang & $\begin{array}{c}500.000- \\
2.500 .000\end{array}$ \\
\hline & & Tinggi & $>2.500 .000$ \\
\hline
\end{tabular}

\subsection{Penentuan data latih}

Dari data nasabah yang ada yang akan dijadikan sebagai data latih terdapat 9 data nasabah yang t. Berikut 
$=0$

\subsection{Hitung gain dan entropy}

Dalam menghitung gain entropy dapat dilakukan sebagai berikut, dimulai dengan node akar.

Entropy untuk semua

E(semua)

$=-\left(\left(p(y a \mid\right.\right.$ semua $) x \log _{2} p(y a \mid$ semua $\left.)\right)$

$+\left(p(\right.$ tidak $\mid$ semua $) x \log _{2} P($ tidak $\mid$ semua $\left.\left.)\right)\right)$

$E($ semua $)=-\left(\left((6 / 9) x \log _{2}\left(\frac{6}{9}\right)\right)\right.$

$$
\left.\left.+(3 / 9) x \log _{2}(3 / 9)\right)\right)
$$

$=0.918$

Entropy untuk jenis kelamin laki-laki

E(semua laki-laki $_{10}$

$=-\left(\left(p(y a \mid l a k i-\operatorname{laki}) X \log _{2} p(y a \mid l a k i-\right.\right.$ laki $)$

$+\left(p(\right.$ tidak $\mid$ laki $-\operatorname{laki}) X \log _{2} p($ tidak $\mid$ laki - laki $\left.\left.)\right)\right)$

$E\left(\right.$ semua $_{\text {laki-laki }}$

$$
=-\left(\left(\frac{4}{4}\right) \times \log _{2}\left(\frac{4}{4}\right)+\left(\left(\frac{4}{0}\right) X \log _{2}\left(\frac{4}{0}\right)\right)\right)
$$

Tabel 3 hasil perhitungan entropy dan gain untuk node akar

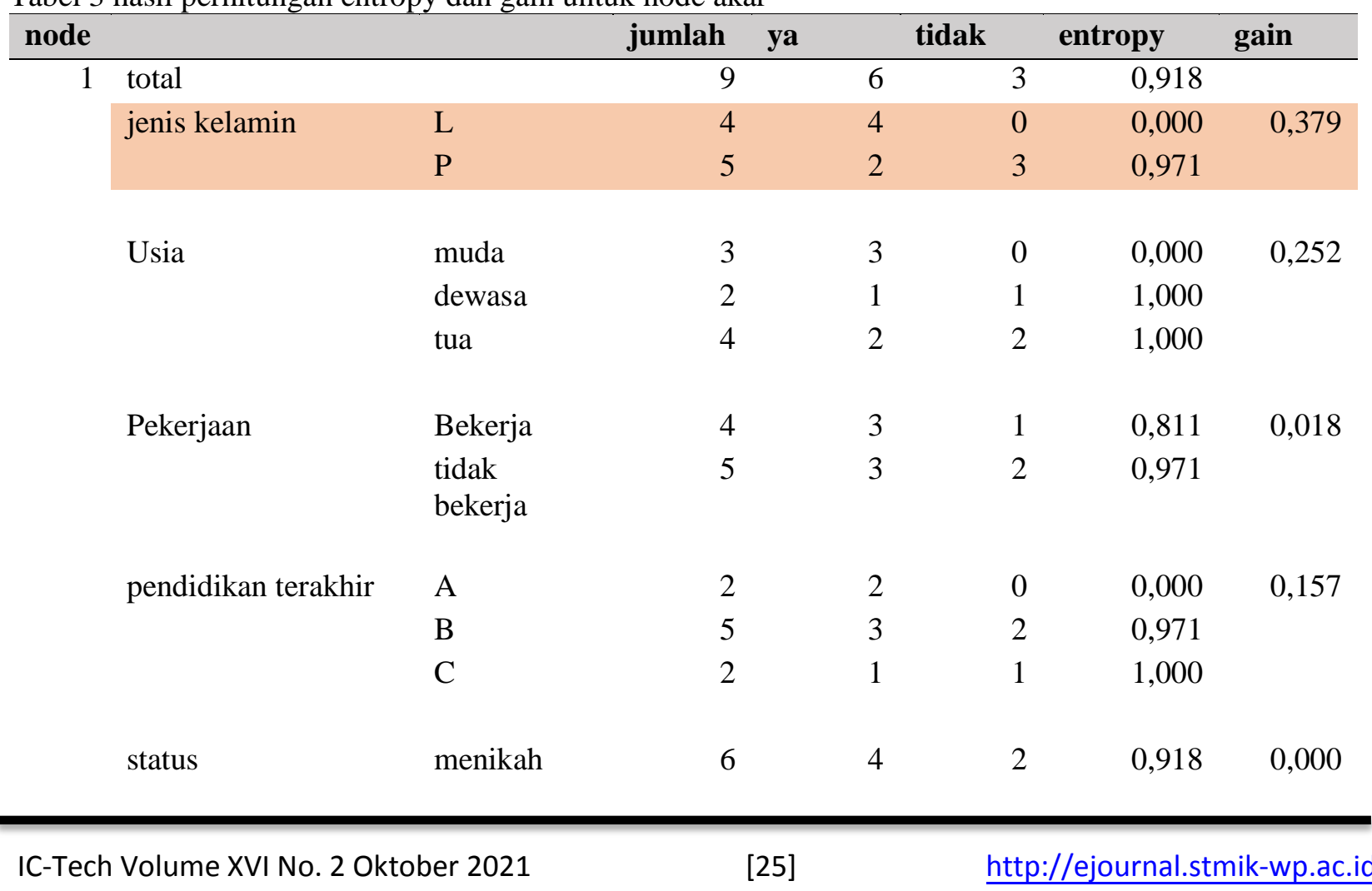

$=-\left((p\right.$ (ya|perempuan $) X \log _{2} p$ (ya|perempuan $)$

$+(p$ (tidak $\mid$ perempuan $) X \log _{2} p($ tidak $\mid$ Perempuan $\left.\left.)\right)\right)$

$$
\begin{array}{r}
\text { E(semua } \text { permpuan } \\
\qquad=-\left(\left(\frac{2}{5}\right) \times \log _{2}\left(\frac{2}{5}\right)\right. \\
+\left(\left(\frac{3}{5}\right) \times \log _{2}\left(\frac{3}{5}\right)\right)
\end{array}
$$

$=0.971$

G(semua,Jenis kelamin)

$=E($ semua $)$

- $\left(\left(p(\right.\right.$ Laki - laki $\mid$ semua $) X E\left(\right.$ semua $\left.\left._{\text {Laki-laki }}\right)\right)$

$+(p($ Perempuan $\mid$ semua $) X$ E (semua perepmpuan $))$

$=0.918-((4 / 9) \times(0))+((5 / 9) \times 0.971)$

$=0.379$ 


\begin{tabular}{lllllll} 
& $\begin{array}{l}\text { belum } \\
\text { menikah }\end{array}$ & 3 & 2 & 1 & 0,918 & \\
setoran awal & rendah & 2 & 1 & 1 & 1,000 & 0,029 \\
& sedang & 4 & 3 & 1 & 0,811 & \\
& tinggi & 3 & 2 & 1 & 0,918 & \\
\hline
\end{tabular}

Tabel 3 hasil perhitungan entropy dan gain untuk node akar, menunjukkan nilai gain tertinggi adalah jenis kelamin. Maka dari itu jenis kelamin dijadikan node akar. Selanjutnya data akan dipecah menjadi 2 yaitu " Laki-laki " dan “ Perempuan". Hasil pohon yang dibentuk disajikan pada gambar 3. Pemisah data Tabel 4 hasil pemisahan data oleh fiur " jenis kelamin didapatkan dari fitu jenis kelamin dapat diliha pada tabel 4. Sebagai berikut:

\begin{tabular}{lllllll}
\hline $\begin{array}{l}\text { jenis } \\
\text { kelamin }\end{array}$ & usia & pekerjaan & $\begin{array}{l}\text { pendidikan } \\
\text { terakhir }\end{array}$ & status & setoran awal & keaktifan \\
\hline L & MUDA & $\begin{array}{l}\text { TIDAK } \\
\text { BEKERJA }\end{array}$ & B & $\begin{array}{l}\text { BELUM } \\
\text { MENIKAH }\end{array}$ & SEDANG & YA \\
L & TUA & $\begin{array}{l}\text { BDAK } \\
\text { BEKERJA }\end{array}$ & B & $\begin{array}{l}\text { MENIKAH } \\
\text { BELUM }\end{array}$ & TINGGI & YA \\
L & DEWASA & BEKERJA & A & MENIKAH & SEDANG & YA \\
& TIDAK & & & & \\
L & MUDA & BEKERJA & B & MENIKAH & RENDAH & YA \\
P & MUDA & BEKERJA & C & MENIKAH & SEDANG & YA \\
& & TIDAK & & & \\
$\mathrm{P}$ & TUA & BEKERJA & C & MENIKAH & TINGGI & TIDAK \\
$\mathrm{P}$ & TUA & BEKERJA & A & MENIKAH & TINGGI & YA \\
P & TUA & BEKERJA & B & MENIKAH & SEDANG & TIDAK \\
& & TIDAK & & BELUM & & \\
$\mathrm{P}$ & DEWASA & BEKERJA & B & MENIKAH & RENDAH & TIDAK \\
\hline
\end{tabular}

Dalam perhitungan entropy dan gain berikutnya, fitur "jenis kelamin" tidak dilibatkan. Berdasarkan pemisahan hasil dari jenis kelamin "Laki-laki" entopry node bernilai nol sehingga dapat dipastikan semua data di node cabang jenis kelamin laki-laki masuk dikelas yang sama dan

Tabel 5. Hasil pemisahan data dari fitur pekerjaan node yang dituju oleh cabang jenis kelamin lakilaki menjadi daun (node terminal) seperti pada gamabar 3, dari pemisahan jenis kelamin "perempuan" maka didapatkan bahawa tidak bekerja keaktifannya adalah "tidak" seperti terlihat pada tabel 5 .

\begin{tabular}{lllllll}
\hline jenis & & \multicolumn{3}{c}{ pendidikan } \\
kelamin & usia & pekerjaan & terakhir & status & setoran awal & keaktifan \\
\hline $\mathrm{P}$ & MUDA & BEKERJA & $\mathrm{C}$ & MENIKAH & SEDANG & YA
\end{tabular}




\begin{tabular}{|c|c|c|c|c|c|c|}
\hline $\mathrm{P}$ & TUA & BEKERJA & A & MENIKAH & TINGGI & YA \\
\hline $\mathrm{P}$ & TUA & BEKERJA & B & MENIKAH & SEDANG & TIDAK \\
\hline $\mathrm{P}$ & TUA & $\begin{array}{l}\text { TIDAK } \\
\text { BEKERJA } \\
\text { TIDAK }\end{array}$ & $\mathrm{C}$ & $\begin{array}{l}\text { MENIKAH } \\
\text { BELUM }\end{array}$ & TINGGI & TIDAK \\
\hline $\mathrm{P}$ & DEWASA & BEKERJA & B & MENIKAH & RENDAH & TIDAK \\
\hline
\end{tabular}

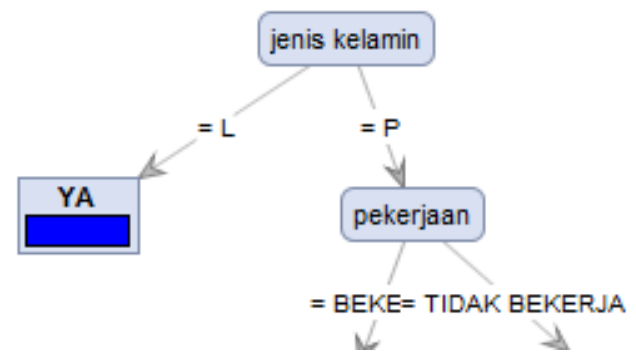

Dari tabel 5 hasil pemisahan data fitur pekerjaan maka didapatkan bahwa " tidak bekerja" maka keaktifan tidak aktif. Untuk node 3. Dapat dihitung seperti pada tabel 6 .

Gambar 3 decision tree untuk node 2

Tabel 6 Hasil perhitungan entropy dan gain untuk node 3

\begin{tabular}{|c|c|c|c|c|c|c|c|c|}
\hline \multicolumn{2}{|c|}{ node } & & \multirow{2}{*}{$\begin{array}{r}\text { jumlah } \\
3\end{array}$} & \multirow[t]{2}{*}{ ya } & tidak & \multicolumn{2}{|r|}{ entropy } & \multirow[t]{2}{*}{ gain } \\
\hline 3 & total & & & & 2 & 1 & 0,918 & \\
\hline & \multirow[t]{3}{*}{ Usia } & muda & 1 & & 1 & 0 & 0,000 & \multirow[t]{3}{*}{0,252} \\
\hline & & dewasa & 0 & & 0 & 0 & 0,000 & \\
\hline & & tua & 2 & & 1 & 1 & 1,000 & \\
\hline & \multirow[t]{3}{*}{$\begin{array}{l}\text { pendidikan } \\
\text { terakhir }\end{array}$} & A & 1 & & 1 & 0 & 0,000 & \multirow{3}{*}{0,918} \\
\hline & & B & 2 & & 0 & 1 & 0,000 & \\
\hline & & $\mathrm{C}$ & 2 & & 1 & 0 & 0,000 & \\
\hline & \multirow[t]{2}{*}{ status } & menikah & 3 & & 2 & 1 & 0,918 & \multirow[t]{2}{*}{0,000} \\
\hline & & menikah & 0 & & 0 & 1 & 0,000 & \\
\hline & \multirow[t]{3}{*}{ setoran awal } & rendah & 0 & & 0 & 0 & 0,000 & \multirow[t]{3}{*}{0,252} \\
\hline & & sedang & 2 & & 1 & 1 & 1,000 & \\
\hline & & tinggi & 1 & & 1 & 0 & 0,000 & \\
\hline
\end{tabular}

Hasil yang didapat di Tabel 6 menunjukkan bahwa gain tertinggi ada difitur "pendidikan" sehingga pendidikan dijadikan sebagai node Tabel 7 Hasil pemisahan data dengan fitur "Pendidikan" internal (node3). Untuk cabangnya digunakan 3 nilai yaitu A, B, C. Dari data pemisah dapat dilihat pada Tabel 7. 


\begin{tabular}{lllllll}
\hline jenis & & \multicolumn{5}{c}{ pendidikan } \\
kelamin & usia & pekerjaan & terakhir & status & setoran awal & keaktifan \\
\hline $\mathrm{P}$ & MUDA & BEKERJA & $\mathrm{C}$ & MENIKAH & SEDANG & YA \\
$\mathrm{P}$ & TUA & BEKERJA & $\mathrm{A}$ & MENIKAH & TINGGI & YA \\
$\mathrm{P}$ & TUA & BEKERJA & $\mathrm{B}$ & MENIKAH & SEDANG & TIDAK \\
\hline
\end{tabular}

Dari tabel 7 dapat dilihat bahwa fitur pendidikan terakhir "A" maka keaktifan "Ya", untuk pendidikan "B" maka keaktifan "Tidak" dan untuk pendidikan terakhir " $\mathrm{C}$ " maka keaktifannya adalah "Ya". Hasil akhir dari inuksi decision tree disajikan pada gambar 4 .

\subsection{Membangun decision tree dengan algoritma ID3}

Setelah dilakukan proses perhitungan Gain dan Entropy dapat dihasilkan decision tree seperti pada gambar 4 .

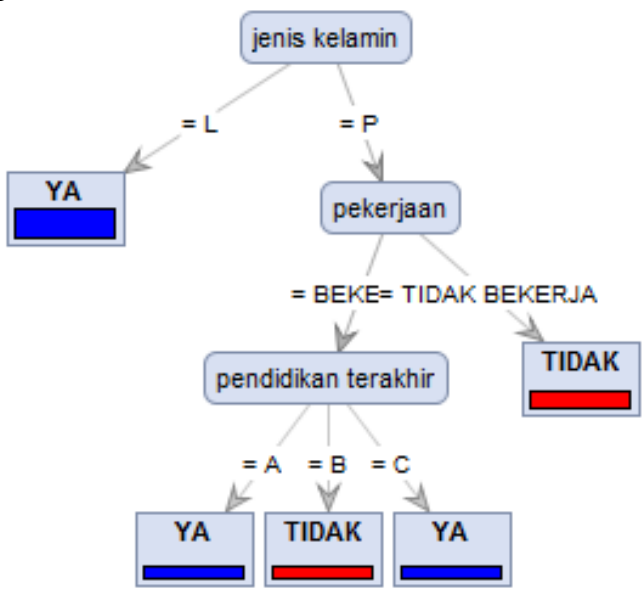

Gambar 4. Decision tree untuk kasus

Aturan yang diperoleh dari pohon keputusan pada gambar 5. Dengan berdasarkan atribut yang digunakan untuk keaktifan nasabah adalah sebagai berikut:

1. IFJenis kelamin $=\mathrm{L}$ Then keaktifan =ya

2. IF Jenis kelamin $=P$ And Pekerjaan=Tidak Bekerja Then keaktifan $=$ tidak
3. IF Jenis Kelamin $=\mathrm{P}$ And Pekerjaan $=$ Bekerja And Pendidikan $=$ A Then $=$ ya

4. IF Jenis Kelamin = P And Pekerjaan $=$ Bekerja And Pendidikan $=$ B Then $=$ Tidak

5. IF Jenis Kelamin $=\mathrm{P}$ And Pekerjaan $=$ Bekerja And Pendidikan $=\mathrm{C}$ Then $=$ ya

Dari pohon keputusan yang diperoleh pada gambar 4. Nasabah yang akatif dalam penabungan dapat dilihat dari deskripsi gambar pohon keputusan seperti gambar 5 dibahwah ini

\section{Tree}

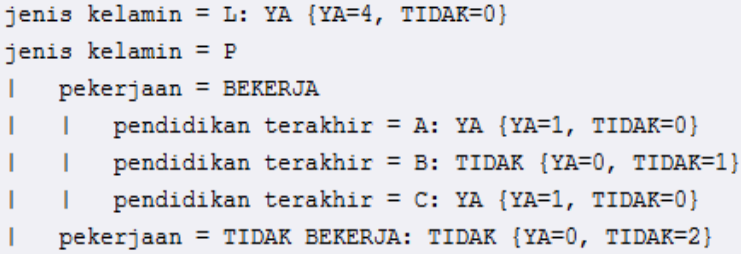

Gambar 5 Deskripsi Pohon Keputusan

\section{Kesimpulan dan Saran}

Pohon keputusan yang dihasilkan oleh algoritma ID 3 dengan pohon yang lebih sederhana setelah dilakukan proses pemangkasan, variasi data yang digunakan bisa bersifat komplit. Dari penelitian ini dihasilkan 5 aturan dengan output keaktifan dari nasabah penabungan. Node akar yang dihasilkan adalah jenis kelamin. Pada penelitian selanjutnya, perlu dikaji dengan kondisi data yang lebih banyak dan atribut yang lebih banyak pula. Selain itu metode seleksi atribut lain seperti forward selection, backward elimination. 


\section{DAFTAR PUSTAKA}

adiana, julce sidette, eko sediyono, dan oky dewi nurhayati. 2014. "pendekatan metode pohon keputusan menggunakan algoritma ID3 untuk sistem infromasi pengukuran kinerja PNS." sistem informasi bisnis 02 (1): 75-86.

fauziah, dedy hartama, dan irfan damanik sudahri. 2020. "analisa kepuasan pelanggan menggunakan klasifikasi data mining." brahmana 2 (1): 41-48.

Febtadianrano, Hakam Putro, retno tri vulandari, dan wawan laksito. 2020. "penerapan metode naive bayes untuk klasifikasi pelanggan." Tikomsin 8 (2): 19-24.

Inda, Putri sari, dan muhammad nasir. 2019. “implementasi model decision tree menggunakan algoritma ID3 untuk menentukan strategi pemasran universitas bina darma palembang." bina darma conference on computer science 1 (1): 739-754.

izzaty, annisak jamhur. 2016. "penerapan data mining untuk menganalisa jumlah pelanggan aktif dengan menggunakan algoritma c4.5." Majalah Ilmiah 23 (2): 12-20.

Pudjo, Prabowo widodo, Tria Rahmadya Handayanto, dan Helawati. 2013. Penerapan data mining dengan matlab. bandung: Rekayasa Sains.

santoso, T.B. 2014. "analisa dan penerapan metode $\mathrm{C} 4.5$ untuk prediksi loyalitas pelanggan." universitas satya negara indonesia.

subhan, muhamad efendi, dan helmie arif wibawa. 2018. "prediksi penyakit diabetes menggunakan algoritma ID3 dengan pemilihan atribut terbaik." Juita 6 (1): 29-36.

Tama, B.A. 2015. "Data mining for predicting coustomer statisfaction." $J$ Theor appl Inf Technol 75 (1): 3-7.

Ulin, Khilyanti fitri, dan Azizah Fatmawati. 2019. "Sistem Ifnromasi pelanggan pada bengkel marno jaya motor." teknik elektro 19 (1): 29-35. 